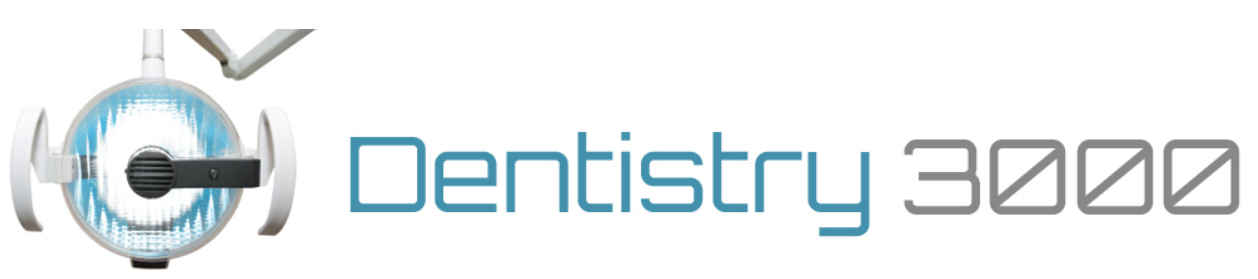

\title{
Comparison of root canal length measurement methods in primary teeth
}

\author{
Mine Koruyucu ${ }^{1}$, Merve Bayram ${ }^{2}$, Yelda Kasımoğlu ${ }^{1}$, Figen Seymen ${ }^{3}$
}

${ }^{1}$ Research Assistant, Istanbul University, Faculty of Dentistry, Department of Pedodontics, Istanbul, Turkey

${ }^{2}$ Assistant Professor, Istanbul Medipol University, Faculty of Dentistry, Department of Pedodontics, Istanbul, Turkey

${ }^{3}$ Professor, Istanbul University, Faculty of Dentistry, Department of Pedodontics, Istanbul, Turkey

\section{Abstract}

Objectives: The purpose of this study was to evaluate the accuracy of conventional radiography, intraoral digital radiovisiography and electronic apex locator in determining the working length of root canals in primary teeth (in-vivo) and to compare the results with scanning electron microscopy measurements (ex-vivo). Materials and Methods: This study was conducted on 50 primary molar teeth. Standard endodontic access cavity preparations were prepared and the actual length was calculated by calibrated investigators. Working lengths were determined by using conventional radiography, RVG and apex locator in a total of 116 root canals. After the extraction of the teeth, each canal length was determined by using SEM. Data were analysed statistically by using Oneway Anova, Tukey HDS, Student $t$ test and Bonferroni tests. Results: The mean root length measurements with conventional radiography were significantly higher than apex locator, RVG and SEM. The accuracy of apex locator and RVG were higher than conventional radiography in determining the working length in primary teeth. Conclusions: The electronic apex locators provide an acceptable level of accuracy in determining root canal length in primary teeth. Clinical Relevance: The purpose of this study was to evaluate the accuracy of conventional radiography, intraoral digital radiovisiography and electronic apex locator in determining the working length of root canals in primary teeth and,to compare the results with scanning electron microscopy measurements.
Citation: Koruyucu M, et al. (2018) Comparison of root canal length measurement methods in primary teeth. Dentistry 3000. 1:a001 doi:10.5195/d3000.2018.83

Received: March 2, 2018

Accepted: April 23, 2018

Published: July 13, 2018

Copyright: (C2018 Koruyucu M, et al. This is an open access article licensed under a Creative Commons Attribution Work 4.0 United States License.

Email: mine.yildirim@istanbul.edu.tr

\section{Introduction}

The primary objective of pulpectomy of primary teeth is to retain teeth with irreversible pulp pathosis in a symptom free state and maintain the integrity of the arch form [1, 2]. However, a number of reasons, such as the complex anatomic morphology of the root canal system in primary teeth, innate physiological root resorption, the close proximity of the permanent successor tooth and the difficulty of producing satisfactory radiological images of primary tooth apices makes it difficult to achieve proper treatment [3].
Radiography is among the most common and widely used techniques for root canal length determination $[4,5]$. Use of radiography to calculate root canal length may not always lead to accurate results especially in case of physiological resorption of primary teeth. Instrumentation and/or overfilling becomes much more possible if there is a mistake in measurement technique, thus the germ of a permanent tooth might get damaged $[4,6,7]$. The overfilled material can retain after natural exfoliation of the primary tooth [8]. Furthermore, poor cooperation of children makes it difficult to take a radiograph with acceptable diagnostic value $[4,5]$.
Proper detection of the working length is very important before pulpectomy in primary teeth. Due to limitations of radiographic interpretation and high possibility of over-instrumentation of the unevenly resorbed roots and subsequent overfilling, the use of electronic apex locators is recommended regardless of the stage of root resorption [7].

Working length determination is an extremely relevant factor for the success of root canal treatments. To achieve best results, the narrowest part of the root canal where the width of blood vessels are smaller and the possibility of healing is highest, namely apical constriction or api-
(cc)BY

ULLIS D-Sorle
New articles in this journal are licensed under a Creative Commons Attribution 4.0 United States License.

This journal is published by the University Library System, University of Pittsburgh as part of its D-Scribe Digital Publishing Program and is cosponored by the University of Pittsburgh Press. 


\begin{tabular}{|l|l|}
\hline \multicolumn{2}{|l|}{ Table 1: The mean root canal length } \\
\hline Method & $\begin{array}{l}\text { Root Canal Length } \\
\text { mean } \pm \text { SD }\end{array}$ \\
\hline Apex locator & $12.96 \pm 1.86$ \\
\hline Conventional radiography & $13.58 \pm 1.68$ \\
\hline RVG & $12.91 \pm 1.88$ \\
\hline SEM & $12.82 \pm 1.96$ \\
\hline One-way ANOVA & ${ }^{* *} p<0.001$ \\
\hline
\end{tabular}

cal foramen are prepared [9]. In theory, the canal terminus is regarded as the cemento-dentinal junction, even though it is not possible to detect it clinically [10]. Therefore, the apical terminus used is minor foramen whose location is around $0.5-1.0 \mathrm{~mm}$ other than the radiographic apex [1113].

Generally, the conventional radiographic method has been used to determine the root canal length $[12,14]$. However, this method has some disadvantages, such as the superposition of anatomical structures and image distortions, and the film processing time [15]. While producing images, not a radiographic film but a sensor is used in the digital radiographic method. This method is more advantageous than the conventional one, as it is faster in image acqusition, its amount of radiation is less and it allows image editing, making it easy to examine the details $[16,17]$.

The apical foramen can be evaluated with an electronic apex locator, but only the radiographic apex can slightly be displayed by radiographs $[5,18]$. Electronic apex locator, which helps to locate the file position in the canal, has been used clinically for more than 40 years [19-21]. Several genera- tions of electronic apex locators have evolved [20]. There is no indication in the literature whether there is any difference in utilization the electronic apex locators in permanent or primary teeth, and as they prevent using radiation more than needed, electronic apex locators are regarded as safe, painless, and helpful. As a result, its use in primary teeth is recommended [5].

The objective of this study was to evaluate the accuracy of conventional radiography, intraoral digital radiovisiography and electronic apex locator in determining the working length of root canals in primary teeth (in-vivo) and to compare the results with scanning electron microscopy measurements (ex-vivo).

\section{Materials and Methods}

The study was approved by the Ethics Committee of the Istanbul University, Medical Faculty (No:2012/1738-1298). Fifty extracted human primary molar teeth (116 root canals) referred for extraction to Istanbul University, Faculty of Dentistry, Department of Pedodontics because it is not possible to restore them after caries are removed or when there is a root with resorption greater than twothirds were selected following clinical and radiographic examination. Primary molars which had abnormal root morphology and evidence of fractures were excluded from the study.

Two calibrated pediatric dentist (MK, MB) carried out dental examinations. Intra-examiner calibration was performed by repeating examinations of 10 teeth after an interval of 1 week. Kappa values for intra-examiner consistency were $95.5 \%$ for teeth. The inclusion criteria for teeth selection were as follows: teeth have to demonstrate extensive caries, show the presence of two-thirds of the root length radiographically, and have adequate tooth structure to be restored. Also there should be no radiographic and clinical evidence of pulp pathology (resorption, spontaneous pain, tenderness to percussion or palpation, swelling, sinus tract, pathologic mobility etc.). During the treatment, the teeth were anesthetized and the endodontic access was performed using high speed diamond burs. The canals were initially explored with \#10 Kfiles (Mani, Tochigi, Japan).

After extirpating the pulp with a barbed broach, the canals

\begin{tabular}{|l|c|}
\hline \multicolumn{2}{|l|}{ Table 2: Post-hoc evaluations of the methods } \\
\hline Method & $p$ \\
\hline Apex locator/Conventional radiography & $0.001^{* *}$ \\
\hline Apex locator/ RVG & 1.000 \\
\hline Apex locator / SEM & 0.992 \\
\hline Conventional radiography / RVG & $0.001^{* *}$ \\
\hline Conventional radiography / SEM & $0.001^{* *}$ \\
\hline RVG / SEM & 1.000 \\
\hline Bonferroni test & ${ }^{* *} p<0.01$ \\
\hline
\end{tabular}




\begin{tabular}{|c|c|c|c|c|c|c|c|}
\hline Method & Age 5 & Age 6 & Age 7 & Age 8 & Age 9 & Age 10 & $p$ \\
\hline & mean \pm SD & mean $\pm \mathrm{SD}$ & mean \pm SD & mean \pm SD & mean \pm SD & mean \pm SD & \\
\hline Apex locator & $13.42 \pm 0.87$ & $13.62 \pm 1.9$ & $11.90 \pm 1.33$ & $13.39 \pm 2.18$ & $11.50 \pm 1.20$ & $12.43 \pm 1.55$ & $0.001^{* *}$ \\
\hline $\begin{array}{l}\text { Conventional } \\
\text { radiography }\end{array}$ & $14.00 \pm 1.04$ & $14.18 \pm 1.36$ & $12.90 \pm 1.17$ & $13.82 \pm 2.26$ & $11.50 \pm 1.20$ & $13.43 \pm 1.22$ & $0.001^{* *}$ \\
\hline RVG & $12.85 \pm 0.89$ & $13.63 \pm 1.76$ & $11.82 \pm 1.58$ & $13.47 \pm 2.2$ & $10.93 \pm 0.76$ & $12.74 \pm 1.57$ & $0.001^{* *}$ \\
\hline SEM & $12.83 \pm 1.21$ & $13.25 \pm 2.14$ & $11.65 \pm 1.34$ & $13.39 \pm 2.38$ & $11.28 \pm 0.55$ & $13.19 \pm 1.36$ & $0.004^{* *}$ \\
\hline$p$ & 0.233 & $0.011^{*}$ & $0.001^{*}$ & 0.058 & $0.001^{* *}$ & $0.001^{*}$ & \\
\hline
\end{tabular}

were irrigated with saline solution then dried with cotton pellets without any attempt to dry the canal. The length of the root canals were measured with one of the fitting K-type file, sized between 15-40 (Mani, Tochigi, Japan). After that, a silicone stop was adjusted to the reference, and the distance between stop and file tip was measured with endodontic ruler by magnifying loupes. The reference point was marked on the coronal portion of the roots with a fine paint marker to facilitate accurate reinsertion of the files. Root canal length for each tooth was measured with a scale in milimeters by all methods (intraoral periapical radiography, RVG and electronic apex locater before extraction, SEM after extraction) (Picture 1). The measuring precision was set to $0.5 \mathrm{~mm}$ and the measurements were recalculated three times for each canal by the same dentist and average value was recorded.

\section{For conventional radiog-} raphy groups; intraoral periapical radiographs were taken by X-ray device operating $8 \mathrm{~mA}$ and $70 \mathrm{Kvp}$
(Kodak, Tokyo, Japan) using paralleling technique The films were then placed parallel to the $X$ ray tube (Trophy, Tokyo, Japan).

The apex locator was used for the electronic measurement (Endo Master, EMS, Switzerland). The labial clip was inserted and Kfile attached to the file holder was smoothly inserted till "apex" appeared on the screen. Then, the rubber stop was placed at the coronal reference, and the measurement of root canal length was done electronically. For RVG groups, after all intraoral preparations RVG (Kodak, Tokyo, Japan) were used to assess the length of the root canal.

When the eruption of permanent teeth start, the teeth that were mobility were extracted. After the teeth had been extracted, they were preserved in $10 \%$ formaldehyde solution. They were numbered and immersed in 5.25\% sodium hypochlorite solution for 15 minutes to get rid of organic residues in root surfaces. Then they were scaled to remove any stain and calculus. In accordance with electron microscopy instruc- tions, the Snonputter technique (Polaron Sputter Coater) for electron microscopy images was used to coat the specimens with gold (150 seconds). SEM under x50 magnification was used to calculate every canal length (Jeol JSM-5600, SEM).

SPSS for Windows, version 10.0 was run for all statistical analyses (SPSS, Chicago, USA). Data were analysed statistically by using Oneway Anova, Tukey HDS, Student t test and Bonferroni tests post-hoc analysis. A P-value $<0.05$ was considered statistically significant.

\section{Results}

A statistically significant difference was found between the mean root canal length of the methods ( $p<0.01$ ) (Table 1). The root canal measurement average of the conventional method was found significantly higher than the apex locator ( $p: 0.001)$, RVG ( $p$ : $0.001)$ and SEM (p: 0.001) measurements $(p<0.01)$. There is no statistically significant difference between the mean apex locator, RVG and SEM measurement, ( $p>$ 0.05) (Table 2).

There is a statistically significant difference between apex locator, conventional method, RVG and SEM averages according to age results $(p<0.001)$. The apex locator averages of ages 6 and 8 were found significantly higher in the 7 years ( $p: 0.008)$ and 9 years ( $p: 0.028)(p<0.05, p<0.01)$. The conventional methods of 9 and 7 years were significantly lower than 


\begin{tabular}{|l|l|l|l|l|l|l|}
\hline Table 4. Post-hoc evaluation of the methods according to age \\
\hline Method & $\begin{array}{l}\text { Age } \\
\mathbf{5}\end{array}$ & Age 6 & Age 7 & $\begin{array}{l}\text { Age } \\
\mathbf{8}\end{array}$ & Age 9 & Age 10 \\
\cline { 2 - 8 } & $p$ & $p$ & $p$ & $p$ & $p$ & $p$ \\
\hline $\begin{array}{l}\text { Apex locator / Conventional } \\
\text { radiography }\end{array}$ & 0.632 & 0.234 & $0.001^{* *}$ & 0.241 & 1.000 & \\
\hline Apex locator/ RVG & & & & & & $0.001^{* *}$ \\
\hline Apex locator/SEM & 1.000 & 1.000 & 1.000 & 1.000 & $0.016^{*}$ & 0.594 \\
\hline Conventional radiography/RVG & 0.406 & 0.582 & 1.000 & 1.000 & 1.000 & $0.002^{* *}$ \\
\hline Conventional radiography/SEM & 0.267 & 0.130 & $0.011^{*}$ & 0.349 & $0.016^{*}$ & $0.032^{*}$ \\
\hline RVG / SEM & 0.191 & $0.017^{*}$ & $0.001^{* *}$ & 0.164 & 1.000 & 1.000 \\
\hline Bonferroni test & 1.000 & 1.000 & 1.000 & 1.000 & $0.011^{*}$ & 0.734 \\
\hline
\end{tabular}

5 years ( $p: 0.008), 6$ years ( $p$ : $0.001)$ and 8 years (p: 0.004). The conventional method avetage of the 7 years was significantly lower than that of 6 years ( $p: 0.048$ ) $(p<0.05)$. RVG averages of 6 and 8 years were significantly higher than 7 years ( $p: 0.004)$ and 9 years ( $p: 0.002)(p<0.01)$. The SEM average of the 7 year was significantly lower than the 6 year ( $p: 0.033)$ and the 8 year (p:0.022) (Table 3 ).

The root canal measurement average of the conventional method was significantly higher than the SEM ( $p: 0.017)$ measurements for 6 years old children $(p<0.05)$. The root canal measurement average of the conventional method was found significantly higher than the apex locator ( $p: 0.001)$, RVG ( $p: 0.011)$ and SEM (p:0.001) measurements for 7 years old children $(p<0.01)$. The root canal measurement averages of RVG were significantly lower than the apex locator ( $p: 0.016)$, conventional method ( $p: 0.016$ ) and SEM ( $p: 0.011)$ for 9 years old children $(p<0.05)$. The root canal measurement average of the conventional method was found significantly higher than the apex locator (p:0.001) and RVG ( $p: 0.032)$ for 10 years old children $(p<0.01 ; p<0.05)$. The root canal measurement average of the SEM method was found significantly higher than the apex locator ( $p$ : $0.002)(p<0.01)$ for 10 years old children (Table 3 ).

There is a statistically significant difference between the root canal averages of the methods according to upper and lower jaw $(p<0.01)$ (Table 5$)$. The root canal measurement average of the SEM method was found to be significantly lower than the apex locator ( $p: 0.004)$, conventional method ( $p: 0.005)$ and RVG in the upper jaw ( $p: 0.036)(p<0.05$; $p<0.01)$. The root canal measurement average of the conventional method was found significantly higher than the apex locator ( $p$ : $0.001)$, RVG ( $p: 0.001)$ and SEM ( $p$ : $0.001)$ measurements in the lower jaw $(p<0.01)$ (Table 6).

\section{Discussion}

One of the most significant steps to get successful results in root canal treatment is to determine the length of root canal accurately. Root resorption generally makes apex of root canals in primary teeth ambigious.

In determination of length in a clinical setting, the only practice that is approved globally, accessible and trustworthy is radiography. However, repeated radiographic exposure of pediatric patients before, during, and immediately after the endodontic treatment may cause high concerns. Nevertheless radiography can give misleading results in resorption [5].

Some studies have reported that while measuring mean working length, both digital radiography and apex locator demonstrated almost similar results with the conventional radiographic method in primary molars [5, 22]. Likewise, Krishnan and Sreedharan study how precisely electronic apex locators and conventional radiographic technique determine the root canal length of primary teeth by comparing with the anatomic root canal length of these teeth. The results of this study from conventional radiography and electronic apex locator were similar; intra-class correlation coefficient also showed that both 


\begin{tabular}{|l|l|c|}
\hline Table 6. Post-hoc evaluation of the methods according to jaws \\
\hline Method & Upper jaw & Lower jaw \\
\cline { 2 - 3 } & $p$ & $p$ \\
\hline Apex locator / Conventional rad. & 0.840 & $0.001^{* *}$ \\
\hline Apex locator / RVG & 1.000 & 1.000 \\
\hline Apex locator / SEM & $0.004^{* *}$ & 1.000 \\
\hline Conventional radiography / RVG & 1.000 & $0.001^{* *}$ \\
\hline Conventional radiography / SEM & $0.005^{* *}$ & $0.001^{* *}$ \\
\hline RVG / SEM & $0.036^{*}$ & 1.000 \\
\hline Bonferroni test & ${ }^{* *} p<0.01$ \\
\hline
\end{tabular}

the radiographic and electronic methods are reliable in determining the root canal length and there is no need to use them together [23].

In the study of Subramaniam et al, measured root canal lengths in primary teeth obtained from four different techniques are compared. The conclusion of the study is that reliable and precise root canal length assessment in primary teeth is possible by the digital radiographic and apex locator technology. Moreover, these methods increase both the safety of endodontic treatment and comfort in children [24].

In one laboratory study, Mello-Moura et al compared the accuracy of four different methods in determining root canal length. The study demonstrated that among all the methods the electronic apex locators provided the most accurate root canal length results, however in case electronic resources are unavailable the combination of radiographic and tactile sense methods might be an alternative as the results were satisfactory [25].

The existence of root resorption is an important charac- teristic of pulpectomy in primary teeth. It is hard to radiologically asses the small areas of resorption especially if the resorption is on buccal/lingual aspects of the root. To discard the disadvantages of radiographic assessment in these cases, electrical root length determination may be used.

Mente et al. evaluated the accuracy of an electronic apex locater device in initial resorption of primary incisors and concluded that whether there was resorption in primary teeth did not affect how accurate the electrical measurement of root canal length invitro [26]. Another study comparing two different root canal measuring device in primary teeth with and without resorption concluded that these devices did not provide reliable data. However, these apex locators may be useful in primary root canal therapy in case other diagnostic measures support them. Additional in vivo assessments of them in primary teeth need to be performed [27].

Apex locator was more likely to miscalculate root length in primary molars with root resorption than direct canal measurement, yet Root ZX (Morita, USA) type apex locator calculated accurately in cases in which root resorption was less than one third of root length in primary molar teeth [28]. In the study of Bel- trame et al, the Root ZX apex locator was studied in primary molar teeth (with or without root resorption) to analyze its in vivo and ex vivo accuracy. As a conclusion, it was not significant that whether there was root resorption or not, as in both cases the Root ZX apex locator measured the root canal working length $\pm 1 \mathrm{~mm}$ in primary molars, in vivo and ex vivo [29]. This conclusion backs up other ex vivo studies as its results confirmed that electronic apex locators can be used to measure canal length in primary teeth $[25,50]$. In addition to that, Bahrololoomi et al. showed that the accuracy of Root ZX electronic apex locator was high in the primary anterior teeth despite root resorption. Therefore, using this device as an adjunct is recommended for root canal length measurements in primary anterior teeth [4].

Leonardo et al. evaluated ex vivo accuracy of two different root canal measuring devices in measuring root canal length of primary incisors and molar teeth that have physiological root resorption. They concluded that electronic apex locators are effective and correct when root canal length of primary incisor or primary molar teeth (whether or not they have root resorption) are determined because of the results of the electronic ones were almost perfectly parallel to the actual root canal length measurements [30]. 


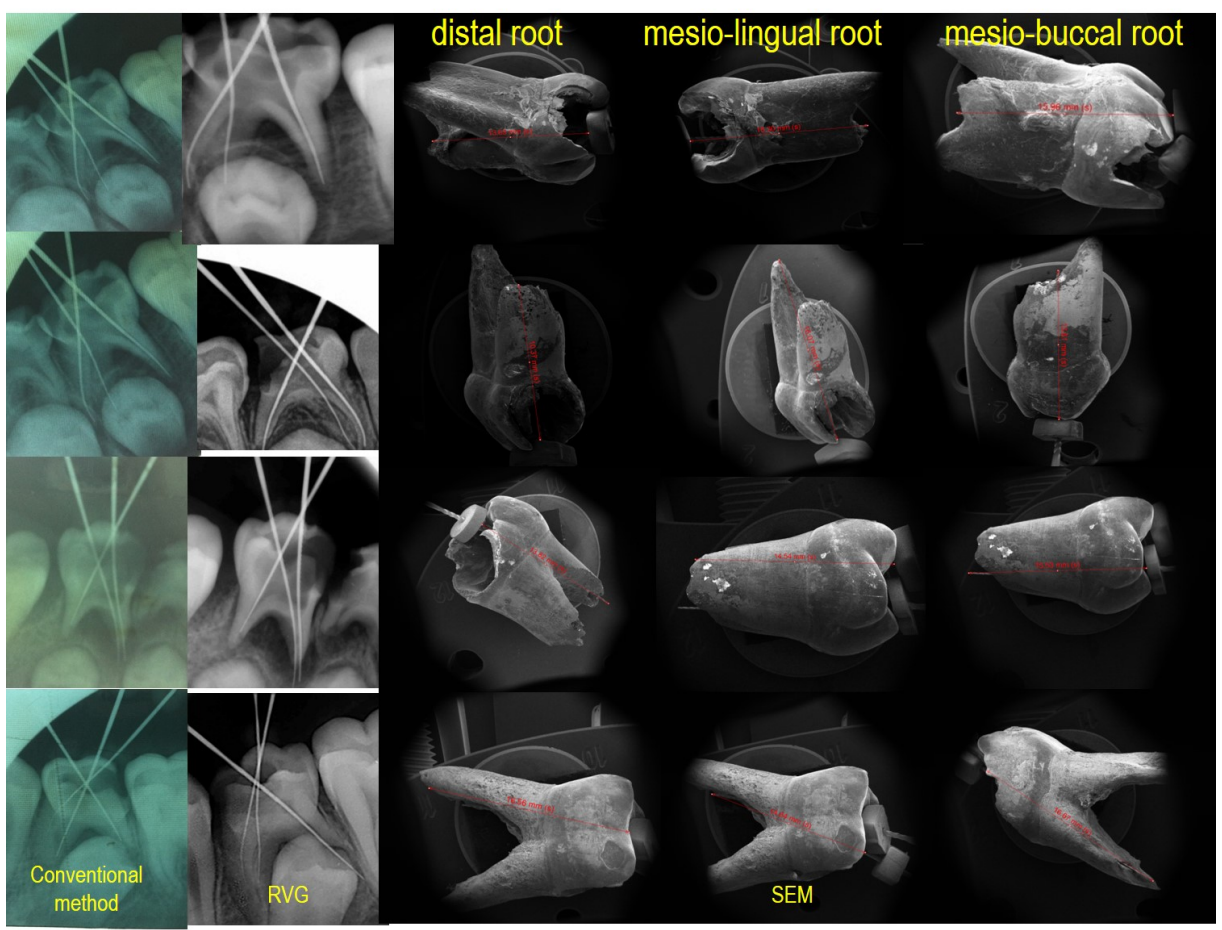

Figure 1. Root canal length measurement for three methods.

In addition to clinical and laboratory studies in primary teeth, studies have been carried out on permanent teeth and different results have been obtained. Esmaeili et al. aimed to compare the accuracy of digital and conventional radiographic techniques in the assessment of the endodontic working length in premolar teeth and concluded that the accuracy of digital and conventional radiography techniques were similar in determination of working length [31]. According to another study findings showed that although there was a significant difference between experimental method and actual working length but electronic apex locator showed the most accurate reading when compared to actual working length in premolar teeth [32].

Orosco et al compared conventional and digital radio- graphic methods in measurement of the root canal working length of maxillary incisor or canine teeth. They concluded that the root canal working length measured with conventional radiographic method were more accurate than the ones obtained with the digital radiographic method [15]. Diwanji et al. compared radiographic method and electronic method with apex locator in determining exact working length of young permanent root canal. Then, the results from these methods were compared to the actual length from histological sections under stereomicroscope. In the light of these comparisons, apex locator was decided to be more reliable and precise than the digital radiography [33].

Mittal et al. compared the accuracy of digital radiograph exposed with paralleling technique, 6 th generation apex locator, tac- tile method, paper point method, combined electronic and radiographic working length and combined electronic, tactile and paper point working length method to determine the working length in permanent teeth with open apex. In the end they found that a combination of electronic tactile and paper point methods in open apex increases the accuracy of working length determination [34].

Martins et al. published a review of compared the radiographic apex locators and radiographs in permanent dentition. They reported that electronic apex locators were mostly more useful than radiography when there is a respective anatomic reference point (for example, the apical constriction or apical foramen) and when radiography was only method in determining working length, most of the times more radiographs were needed than using electronic apex locator. This study shows that in primary teeth (with and without initial root resorption) interexaminer reproducibility of electrical assessment of root canal length in vitro was high. In comparison with the radiographic results, the accuracy of the working length was higher [35].

This study evaluates the accuracy of conventional radiography, intraoral digital radiovisiography and electronic apex locator in determining the working length of root canals in primary teeth (in vivo) and to compare the results with scanning electron microscopy measurements (ex vivo). The difference of this study from the 
other studies is that there is no study which is compared with SEM in the literature. In addition, the findings of comparison of methods according to age and jaws were not found in other literature.

Besides different results are obtained according to the methodological differences in the research it can be concluded that electronic apex locators provide an acceptable level of accuracy in determining root canal length in primary teeth. In this study the accuracy of apex locator and RVG were higher than conventional radiography in determining the working length in primary teeth.

\section{Conclusion}

The results confirm that electronic apex locaters can accurately determine the root canal length in primary teeth.

\section{Acknowledgements}

We would like to thank the Dt. Pelin Barlak for his contribution to the research.

\section{References}

1. American Academy of Pediatric Dentistry Clinical Affairs Committee--Pulp Therapy Subcommittee; American Academy of Pediatric Dentistry Council on Clinical Affairs (20082009) Guideline on Pulp Therapy for Primary and Immature Permanent Teeth. Pediatr Dent 30(7):170-4.
2. Rodd HD, Waterhouse PJ, Fuks AB, Fayle

SA, Moffat MA; British Society of Paediatric Dentistry (2006) Pulp therapy for primary molars. Int J Paediatr Dent 16(1):15-23.

3. Carotte P (2005) Endodontic Treatment for Children. British Dental Journal 198(1):9-15.

4. Bahrololoomil Z, Soleymani AA, Modaresi J, Imanian M, Lotfian M (2015) Accuracy of an electronic apex locator for working length determination in primary anterior teeth. Jornal of Dentistry, Tehran University of Medical Sciences

12(4):243-8.

5. Oznurhan $F$, Unal M, Kapdan A, Ozturk C, Aksoy $S$ (2015) Clinical evaluation of apex locator and radiography in primary teeth. Int J Paediatr Dent 25:199203.

6. Jerrel RG, Ronk SL (1982) Develeopmental arrest of succedaneous tooth following pulpectomy in a primary tooth. J Pedod 6(4):337-42.

7. Ahmed HMA (2013) Anatomical challenges, electronic working length determination and current developments in root canal preparation of primary molar teeth. Int Endod J 46:1011-1022.
8. Chawla HS, Setia S, Gupta N, Gauba K, Goyal A (2008) Evaluation of a mixture of zinc oxide, calcium hydroxide, and sodium fluoride as a new root canal filling material for primary teeth. J Indian Soc Pedod Prev Dent 26(2):53-8.

9. Ricucci D, Langeland K (1998) Apical limit of root canal instrumentation and obturation, part 2. A histological study. Int Endod J 31:394-409.

10. Burch JG, Hulen S (1972) The relationship of the apical foramen to the anatomic apex of the tooth root. Oral Surg Oral Med Oral Pathol 34:262-268.

11. Kuttler Y (1958) A precision and biologic root canal filling technic. J Am Dent Assoc 56 : $38-50$.

12. Katz A, Tamse A, Kaufman AY (1991) Tooth length determination: a review. Oral Surg Oral Med Oral Pathol 72:238-242.

13. Morfis A, Sylaras SN, Georgopoulou M, Kernani M, Prountzos F (1994) Study of the apices of human permanent teeth with the use of a scanning electron microscope. Oral Surg Oral Med Oral Pathol 77:172176.

14. Stein TJ, Corcoran JF (1992) Radiographic 'working length' revisited. Oral Surg 
Oral Med Oral Pathol

74:796-800.

15. Orosco FA, Bernardineli $N$, Garcia RB, Bramante CM, Duarte MAH, Moraes IG (2012) In vivo accuracy of conventional and digital radiographic methods in confirming root canal working length determination by Root ZX. J Appl Oral Sci 20(5):522-525.

16. Ellingsen $M A$, Hollender LG, Harrington GW (1995) Radiovisiography versus conventional radiography for detection of small instruments in endodontic length determination. II. In vivo evaluation. J Endod 21(10):516-20.

17. Shearer AC, Horner K, Wilson $\mathrm{NH}$ (1990) Radiovisiography for imaging root canals: an in vitro comparison with conventional radiography. Quintessence Int 21(10):789-94.

18. Kobayashi C. Electronic canal length measurement (1995) Oral Surg Oral Med Oral Pathol Oral Radiol Endod 79:226-231.

19. Alves AM, Felippe MC, Felippe WT, Rocha MJ (2005) Ex vivo evaluation of the capacity of the Tri Auto ZX to locate the apical foramen during root canal retreatment. Int Endod J 38:718-724.
20. Ebrahim AK, Wadachgi $R$, Suda H (2007) Electronic apex locators-review. J Med Dent Sci 54:125-136.

21. Goldberg F, Marroquin BB, Frajlich S, Dreyer C (2005) In vitro evaluation of the ability of three apex locators to determine the working length during retreatment. J Endod 31:676-678.

22. Neena IE, Ananthraj A, Praveen $P$, Karthik $V$, Rani $P$ (2011) Comparison of digital radiography and apex locator with the conventional method in root length determination of primary teeth. J Indian Soc Pedod Prev Dent 29(4):300-304.

23. Krishnan IS, Sreedharan $S$ (2012) A comparative evaluation of electronic and radiographic determination of root canal length in primary teeth: An in vitro study. Contemporary Clinical Dentistry 3(4):416-420.

24. Subramaniam $P$, Konde $S$, Mandanna DK (2005). An in vitro comparison of root canal measurement in primary teeth. J Indian Soc Pedod Prev Dent 23(3):124-125.

25. Mello-Moura ACV, MouraNetto C, Araki AT, GuedesPinto AC, Mendes FM (2010) Ex vivo performance of five methods for root canal length determination in primary anterior teeth. Int Endod J 43:142-147.

26. Mente J, Seidel J, Buchalla W, Koch MJ (2002) Electronic determination of root canal length in primary teeth with and without root resorption. Int Endod J 35:447-452.

27. Bodur $\mathrm{H}$, Odabaş $\mathrm{M}$, Tulunoglu O, Tinaz AC (2008). Accuracy of two different apex locators in primary teeth with and without root resorption. Clin Oral Invest 12:137-141.

28. Angwaravong $\mathrm{O}$, Panitvisai $P$ (2009) Accuracy of an electronic apex locator in primary teeth with root resorption. Int Endod J 42:115-121.

29. Beltrame APCA, Triches TC, Sartori N, Bolan M (2011) Electronic determination of root canal working length in primary molar teeth: an in vivo and ex vivo study. Int Endod J 44:402-406.

30. Leonardo MR, Silva LAB, Nelson-Filho $P$, Silva RAB, Raffaini MSGG (2008) Ex vivo evaluation of the accuracy of two electronic apex locators during root canal length determination in primary teeth. Int Endod J 41:317-321.

31. Esmaeili F, Akbari FA, Zarandi A (2016) Comparison of accuracy of digital and conventional radiog- 
raphies in determining endodontic working length. SADJ 71(9): 395-397.

32. Mittal $R$, Singla $M G$, Sood A, Singla A (2015) Comparative evaluation of working length determination by using conventional radiography, digital radiography and electronic apex locator. Journal of Restorative Dentistry 3(3):70-75.

33. Diwanji A, Rathore AS, Arora R, Dhar V, Madhusudan A, Doshi J (2014) Working length determination of root canal of young permanent tooth: An invitro study. Annals of Medical and Health Sciences Research 4(4):554-558

34. Mittal P, Jadhav GR, Logani A (2016) Accuracy of different methods to determine working length in teeth with open apex-an ex vivo comparative study. J Dent Specialities 4(1):3945.

35. Martins JNR, Marques $M$, Mata A, Carames J (2014) Clinical efficacy of electronic apex locators: Systematic review. J Endod 40(6):75977. 